\title{
Decreased STEC shedding by cattle following passive and active vaccination based on recombinant Escherichia coli Shiga toxoids
}

\author{
Nadine Schmidt ${ }^{1,3^{*}}$ (D) Stefanie A. Barth', Jana Frahm², Ulrich Meyer ${ }^{2}$, Sven Dänicke², Lutz Geue ${ }^{1 \wedge}$ \\ and Christian Menge ${ }^{1}$
}

\begin{abstract}
The principal virulence factor of Shiga toxin (Stx)-producing Escherichia coli (STEC), the eponymous Stx, modulates cellular immune responses in cattle, the primary STEC reservoir. We examined whether immunization with genetically inactivated recombinant Shiga toxoids ( $r S t \times 1_{\text {MUT }} / r S t \times 2_{M U T}$ ) influences STEC shedding in a calf cohort. A group of 24 calves was passively (colostrum from immunized cows) and actively (intra-muscularly at $5^{\text {th }}$ and $8^{\text {th }}$ week) vaccinated. Twenty-four calves served as unvaccinated controls (fed with low anti-Stx colostrum, placebo injected). Each group was divided according to the vitamin E concentration they received by milk replacer (moderate and high supplemented). The effective transfer of Stx-neutralizing antibodies from dams to calves via colostrum was confirmed by Vero cell assay. Serum antibody titers in calves differed significantly between the vaccinated and the control group until the $16^{\text {th }}$ week of life. Using the expression of activation marker CD25 on $\mathrm{CD}^{+}{ }^{+} \mathrm{CD} 45 \mathrm{RO} \mathrm{O}^{+}$cells and $\mathrm{CD} 8 \mathrm{a}^{\text {hi }} \mathrm{CD} 45 \mathrm{RO}^{+}$cells as flow cytometry based read-out, cells from vaccinated animals responded more pronounced than those of control calves to lysates of STEC and E. coli strains isolated from the farm as well as to rSt $2_{\text {MUT }}$ in the $16^{\text {th }}$ week. Summarized for the entire observation period, less fecal samples from vaccinated calves were $s t x_{1}$ and/ or stx $x_{2}$ positive than samples from control animals when calves were fed a moderate amount of vitamin $\mathrm{E}$. This study provides first evidence, that transfer to and induction in young calves of Stx-neutralizing antibodies by Shiga toxoid vaccination offers the opportunity to reduce the incidence of stx-positive fecal samples in a calf cohort.
\end{abstract}

\section{Introduction}

Enterohemorrhagic Escherichia coli (EHEC), a subset of Shiga toxin-producing E. coli (STEC), is a food-borne pathogen that can evoke life-threatening diseases in humans such as hemorrhagic colitis and hemolytic-uremic syndrome. EHEC serotype $\mathrm{O} 157: \mathrm{H} 7 / \mathrm{H}-$ is implicated in most EHEC outbreaks worldwide. However, human infections by non-O157:H7 serotypes (e.g. O91, O26, O113) frequently occur in Germany and other European countries [1]. The only virulence marker common to all STEC serotypes is the possession of a gene

*Correspondence: Nadine.Schmidt@vetmed.uni-giessen.de

$\wedge$ In memoriam

${ }^{1}$ Friedrich-Loeffler-Institut (FLI)/Federal Research Institute for Animal

Health, Institute of Molecular Pathogenesis, Jena, Germany

Full list of author information is available at the end of the article encoding for Shiga toxin (Stx). Calves get infected orally with a plethora of different STEC strains present in their environment early in life, but rarely develop clinical signs of infection. Many STEC strains are able to colonize the bovine intestine [2-6], including non-O157:H7 [7-9]. Cattle may shed these bacteria for several month in quantities that may be considerably high at some sampling points [10-13] making cattle, besides other ruminants, an important reservoir for STEC strains associated with human diseases. To reduce the risk of STEC entering the food chain, interventions must be applied at several stages starting at cow and herd level and continuing in slaughterhouses, processing plants, distributors, and households $[14,15]$.

Even though previous attempts to develop vaccination strategies in cattle were promising they only partially reduce STEC excretion and the effect was mostly 
restricted to single subpopulations of STEC, e.g. O157 strains $[14,16]$. Long-term studies on anti-Stx antibody titers in serum and fecal STEC shedding by cattle unveiled significantly delayed humoral immune responses following experimental STEC infection [17] and natural exposure [12]. Delayed adaptive cellular immune responses was also shown after experimental STEC infection [17]. The principal STEC virulence factor, the eponymous Stx, modulates cellular immune responses in cattle [18-21]. In vitro and in vivo studies revealed that Stx operates during the early phases of immune activation rather than depressing an established immunity [17, 20, 22, 23]. Current knowledge of STEC shedding dynamics and influences of Stx on immune responses suggests, that Stx may hinder the development of an effective immune response by hitherto immunologically naïve animals upon first STEC contact at early calves' ages.

Inactivation of Stx by genetic modification located within the enzymatically active cleft of Stx resulted in toxoids ( $r S t x 1_{\text {MUT }}$ and $r S t x 2_{\text {MUT }}$ ) with retained antigenicity and immunogenicity but lost immunomodulatory properties in cattle [24]. Immunisation of sows with Stx2e toxoid $[25,26]$ was shown to trigger maternal immunity which protects offspring against edema disease [27] and fully protected the animals when challenged with native Stx2e [28]. Induction of humoral and cellular immune responses by Stx toxoids was also achieved in mice $[29,30]$.

We therefore hypothesized that passive (maternal) and active vaccination against Stx1 and Stx2 confers protection against the toxins' immunomodulating effect and subsequently enables calves to actively mount a rapid immune response against STEC strains circulating in the respective cohort. In order to follow a novel approach to add on current vaccination strategies aiming at reducing STEC shedding by cattle, this study wanted to assess if active and passive immunization with Stx toxoid-based vaccines enables calves (i) to gain and produce Stx-neutralizing antibodies and (ii) to mount a more rapid and effective cellular immune response against STEC strains than unvaccinated controls in a respective cohort (iii) resulting in reduction of STEC shedding. As an essential antioxidant for maintaining the stability of biological membranes and the function of the immune system vitamin $\mathrm{E}$ (vit E) is considered to support adaptive and humoral immune responses [31-34]. Therefore, milk replacer fed to some animals deployed in the study was supplemented with vit $\mathrm{E}$ in higher amounts as usually included in commercially available products to support the effect of the vaccine.

\section{Materials and methods}

Generation of recombinant Shiga toxins and Shiga toxoids Recombinant Stx ( $\mathrm{rStx} 1_{\mathrm{WT}}$ and $\mathrm{rStx} 2_{\mathrm{WT}}$ ) and genetically inactivated recombinant Stx toxoids ( $\mathrm{rStx} 1_{\mathrm{MUT}}$ and $\mathrm{rStx} 2_{\mathrm{MUT}}$ ) were previously generated and tested by Kerner et al. [24]. rStx $1_{\text {MUT }}$ and $r S t x 2_{\text {MUT }}$ preparation were adjusted separately with $\mathrm{NaCl}$ solution (0.89\%) to 0.75 Mio verocytotoxic doses $50 \%\left(\mathrm{CD}_{50}\right)$ equivalents [24] each in $1.4 \mathrm{~mL}$ and frozen at $-20{ }^{\circ} \mathrm{C}$.

\section{Vaccination of cows for colostrum production}

In October and November 2012, 14 cows (Deutsche Holstein) from the dairy herd at the experimental station, FLI Brunswick, served as donors for colostrum to be used in the subsequent year. Five cows had been vaccinated at 9 and 6 weeks before the calculated calving date. To this end, cows received by separate injection in the left and right $M$. gluteus 0.75 Mio $C_{50}$ equivalents of $\mathrm{rStx} 1_{\mathrm{MUT}}$ and of $\mathrm{rStx} 2_{\mathrm{MUT}}$ each in $1.4 \mathrm{~mL} \mathrm{NaCl}$ solution $(0.89 \%)$ freshly mixed with $0.6 \mathrm{~mL}$ aluminum hydroxide (Alu-Gel-S, Serva Electrophoresis GmbH, Heidelberg, Germany). Further 9 cows served as unvaccinated controls. Colostrum was collected from the first 3 milkings after parturition and screened for Stx-neutralizing antibodies by Vero cell neutralization assay (VNA). Pools of colostrum with high (pool VAC+; anti-Stx1 titer 51 001, anti-Stx2 titer 32 856; determined by VNA, see below) and with lower anti-Stx titer (pool VAC-; anti-Stx1 titer 11005 , anti-Stx2 titer 15 811) were collected, aliquoted and stored $\left(-20^{\circ} \mathrm{C}\right)$.

\section{Experimental design, housing and sampling of calves}

In October and November 2013, a total of 48 male Holstein calves born in the dairy herd of FLI Brunswick were alternately assigned to groups of to be $\mathrm{rStx}_{\mathrm{MUT}}$-vaccinated animals (VAC+) and placebo-treated animals $(\mathrm{VAC}-)$, as well as to vit $\mathrm{E}$ high $\left(\mathrm{VitE}_{\mathrm{H}}\right)$ and vit $\mathrm{E}$ moderate $\left(\mathrm{VitE}_{\mathrm{M}}\right)$ feeding groups. The treatments were arranged according to a two by two complete 2 -factorial design and consequently resulted in four experimental groups: $\mathrm{VAC}+\mathrm{VitE}_{\mathrm{H}}(n=11), \mathrm{VAC}-\mathrm{VitE}_{\mathrm{H}}(n=11)$, $\mathrm{VAC}+\operatorname{VitE}_{\mathrm{M}}(n=13)$ and VAC $-\operatorname{VitE}_{\mathrm{M}}(n=13)$.

Directly after birth, calves were separated from dams. In the first $9( \pm 1.5)$ days of life animals were kept separately in calf huts on straw. Thereafter calves were kept in 2 groups in accordance with vit $\mathrm{E}$ feeding assignment with straw bedding. From weaning until the end of the observation period, animals were housed in groups of different sizes irrespective of their group affiliation together with other bull calves of the same age, not included in the trial. Fecal samples were collected in weeks 3, 16, 26 and 55. Serum samples were collected before initial colostrum intake (pre-colostral), between 6 to $24 \mathrm{~h}$ after initial 
colostrum intake (post-colostral), as well as in weeks 3, $11,16,26,55$. For PBMC preparation $16 \mathrm{~mL}$ blood (week 16 and 26) were drawn from the jugular vein into tubes containing $4 \mathrm{~mL} \mathrm{3.8 \%} \mathrm{sodium} \mathrm{citrate} \mathrm{dihydrate} \mathrm{(Sigma-}$ Aldrich $\mathrm{GmbH}$, Deisenhofen, Germany) solution. The vaccination protocol included a combination of passive and active vaccination with recombinant Shiga toxoids $\left(\mathrm{rStx}_{\mathrm{MUT}}\right)$. Directly after birth, VAC+ calves were fed $3 \mathrm{~L}$ of a colostrum pool previously collected from $\mathrm{rStx}_{\mathrm{MUT}}$ vaccinated cows as described above while VAC- calves received colostrum from non-vaccinated cows. In the $5^{\text {th }}$ and $8^{\text {th }}$ week of life VAC+ animals were actively vaccinated with $\mathrm{rStx} 1_{\mathrm{MUT}}$ and $\mathrm{rStx} 2_{\mathrm{MUT}}$ as described above. VAC - animals were placebo-injected with $\mathrm{NaCl}$ solution and adjuvant. After feeding $3 \mathrm{~L}$ colostrum, calves were offered $875 \mathrm{~g} /$ day of milk replacer (MR) supplying 188 and $200 \mathrm{IU}$ all-rac- $\alpha$-tocopheryl acetate $/ \mathrm{kg}$ dry matter (DM) in group $\mathrm{VitE}_{\mathrm{M}}$ and $\mathrm{Vit}_{\mathrm{H}}$, respectively, dissolved in $6 \mathrm{~L}$ of water split into two equal portions (bucket feed) daily until the $9^{\text {th }}( \pm 1.5)$ day of live. The vit $E$ dose fed to $\mathrm{Vit}_{\mathrm{M}}$ group was referred to as "moderate" as the vit E concentration supplied with the feed was above levels of international recommendations for calves of the respective age [35]. However, the dose used was equivalent to the degree of supplementation of milk replacer commercially distributed and used in modern livestock farming. From $10^{\text {th }}$ to $49^{\text {th }}$ day of life $\mathrm{Vit}_{\mathrm{H}}$ calves were offered $840 \mathrm{~g} /$ day MR supplemented with $188 \mathrm{IU}$ and 354 IU all-rac- $\alpha$-tocopheryl acetate/kg DM in group $\mathrm{VitE}_{\mathrm{M}}$ and $\mathrm{VitE}_{\mathrm{H}}$ by automatic calf feeders (Förster-Technik $\mathrm{GmbH}$, Engern, Germany). Vit E fed groups split by vaccination took up comparable average amounts of allrac- $\alpha$-tocopheryl acetate (IU/day: $\mathrm{VAC}+\mathrm{VitE}_{\mathrm{H}}$ 279.2; $\mathrm{VAC}-\mathrm{VitE}_{\mathrm{H}}$ 276.9; VAC $+\mathrm{VitE}_{\mathrm{M}}$ 152.2; VAC- $\mathrm{VitE}_{\mathrm{M}}$ 154.7) throughout the entire period of performance acquisition. From the $9^{\text {th }}$ day calves received hay ad libitum and concentrate up to $2 \mathrm{~kg} /$ day in addition. Drinking water was available for ad libitum intake during the whole experiment. From the $50^{\text {th }}$ day until the end of observation period animals were fed conventionally.

\section{Vero cell cytotoxicity assay (VCA) and Vero cell neutralization assay (VNA)}

The VCA was performed in 96-well microtiter plates (Nunc GmbH, Wiesbaden, Germany) using Vero cells (ATCC CRL 1587, LGC-Promochem GmbH, Wesel, Germany) to determine Vero cytotoxic doses $50 \%\left(\mathrm{CD}_{50} /\right.$ $\mathrm{mL}$ ) [36]. The VNA was used for the quantitation of the neutralizing activity in serum and colostrum against rStx $1_{\mathrm{WT}}$ or $\mathrm{rStx} 2_{\mathrm{WT}}$ as described previously [12]. Serum samples were tested at pre-dilutions of 1:30 and 1:90, colostrum samples at 1:300 and 1:900. At the pre-colostral sampling only a subset of animal's sera $(n=23)$ was tested, at the other samplings all animals were included $(n=48)$. Neutralizing antibody (nAb) titers were determined by multiplying the relative cell activity with the dilution factor when the relative cell activity was $>30 \%$ $\left(\mathrm{rStx} 1_{\mathrm{WT}}\right)$ or $>20 \%\left(\mathrm{rStx} 2_{\mathrm{WT}}\right)$. Samples with a relative cell activity below the detection limit ( $\mathrm{AAb}$ rStx1 = 900; nAb $\mathrm{rStx} 2=600$ ) were given arbitrary nAb titer of half of the lowest detectable value.

\section{PBMC stimulation assay}

Five E. coli and 2 Listeria monocytogenes strains isolated from dams of the experimental herd were cultivated in LB broth (lysogeny broth, Lennox), adjusted to $2 \times 10^{7}$ colony forming units $(\mathrm{cfu}) / \mathrm{mL}$ by optical density and heat inactivated $\left(100^{\circ} \mathrm{C}, 10 \mathrm{~min}\right)$. Aliquots of each lysate were tested for sterility on sheep blood agar (SIFIN diagnostics $\mathrm{GmbH}$, Berlin, Germany) and stored at $-20{ }^{\circ} \mathrm{C}$ until use. E. coli lysates were tested for cytotoxicity by VCA and for stx ${ }_{1}$ and stx $x_{2}$ by PCR. E. coli strain lysates were not cytotoxic except $E$. coli strain $2\left(430 \mathrm{CD}_{50} / \mathrm{mL}\right)$.

Peripheral blood mononuclear cells (PBMC) were isolated as described previously without erythrocytes lysis step [20]. PMBC were suspended in cell culture medium (RPMI 1640 supplemented with 10\% fetal calf serum, $3 \mu \mathrm{M}$ 2-mercaptoethanol, $100 \mathrm{IE} / \mathrm{mL}$ Penicillin, $2 \mathrm{mM}$ L-glutamine) and seeded into Cellstar ${ }^{\circledR}$ 24-well suspension plates (Greiner Bio-One $\mathrm{GmbH}$, Frickenhausen, Germany) at $1 \mathrm{~mL} /$ well $\left(2 \times 10^{6}\right.$ cells $)$. Pure cell culture medium (MC) or cell culture medium supplemented with stimulants (lysates equivalent to final concentration (f.c.) of $1 \times 10^{5} \mathrm{cfu} / \mathrm{mL}$ [17], Concanavalin A (ConA) f.c. $0.75 \mu \mathrm{g} / \mathrm{mL}$, or $r \operatorname{rstx} 1_{\mathrm{MUT}}$ or $\mathrm{rStx} 2_{\mathrm{MUT}}$ f.c. $200 \mathrm{CD}_{50}$ equivalent [24] were added in $1 \mathrm{~mL} /$ well. Plates were incubated for 5 days at $5 \% \mathrm{CO}_{2}$ and $37{ }^{\circ} \mathrm{C}$.

After 5-day incubation, supernatants were collected for further use (see below) and cells gently resuspended with washing buffer (PBS-Dulbecco without $\mathrm{Ca}$ and $\mathrm{Mg}$, Biochrom supplemented with $0.01 \%$ sodium azide). Cell suspension was transferred to V-shape microtiter plates (Greiner Bio-One GmbH, Frickenhausen, Germany), incubated (10 min), and centrifuged $(400 \times g, 3 \mathrm{~min}$, $4{ }^{\circ} \mathrm{C}$ ). Supernatants were removed and cells resuspended with $30 \mu \mathrm{L}$ of the primary monoclonal antibody dilution (anti-CD45RO clone IL-A116 [Bio-Rad AbD Serotec GmbH, Puchheim, Germany], 1:100). Cells were incubated (30 min, $4{ }^{\circ} \mathrm{C}$, in the dark), washed twice, and resuspended with directly labelled antibodies (anti-CD4 Alexa Fluor 647 clone CC8; anti-CD8 $\alpha$ Alexa Fluor 647 clone CC63; anti-CD25 FITC clone IL-A111 [Bio-Rad AbD Serotec GmbH, Puchheim, Germany], 1:200) and secondary antibody solutions (PE labelled $\alpha$-rat IgG Iga $_{\text {([QIAGEN }}$ Leipzig $\mathrm{GmbH}$, Leipzig, Germany], 1:1000; for detection of anti-CD45RO) and incubated again. For isotype 
control, mouse $\mathrm{IgG}_{2 \mathrm{a}}$ (Alexa Fluor 647 [Bio-Rad AbD Serotec GmbH, Puchheim, Germany], 1:200) and mouse $\mathrm{IgG}_{1}$ (FITC [Bio-Rad AbD Serotec GmbH, Puchheim, Germany], 1:200) was used. Addition of PE-labelled $\alpha$-rat $\mathrm{IgG}_{2 \mathrm{a}}$ to a control sample without anti-CD45RO was used to exclude non-specific binding of the indirectly labelled antibody. After washing, dead cells were quantified in the first set of experiments by incubating $50 \mu \mathrm{L}$ cell suspension with $0.75 \mu \mathrm{L}$ propidium iodide (Merck KGaA, Darmstadt, Germany) within MC. The proportions of dead cells were approx. $6 \%$ on average without group differences. At least 5000 cells with unaltered morphology (i.e. events which fell into the non-blast and blast region in the FSC vs. SSC plot) per sample, were assessed by use of a BD FACS Canto ${ }^{\mathrm{TM}}$ II analyzer (BD Biosciences, Heidelberg, Germany). $\mathrm{CD} 4{ }^{+} \mathrm{CD} 45 \mathrm{RO}^{+}$and $\mathrm{CD} 8 \alpha^{\text {hi }} \mathrm{CD} 45 \mathrm{RO}^{+}$blast cells were analyzed for CD25 expression (FlowJo; Tree Star, Inc., San Carlos, CA, USA; see Figure 1 for the gating strategy). Results were expressed as percentage change compared to MC using the formula: (Geometric mean of fluorescence intensity [Geomean] stimulation-Geomean $\mathrm{MC}) /$ Geomean MC $\times 100 \%$.

\section{IFN- $\gamma$ ELISA of cell culture supernatants}

PBMC supernatants were tested for IFN- $\gamma$ protein by ID Screen ${ }^{\circledR}$ ELISA test kit (ID.vet, Grabels) and evaluated following instructions provided by the manufacturer. Optical density (OD) was converted to S/P ratio following the equation: $\mathrm{S} / \mathrm{P}$ ratio $=\left[\mathrm{OD}_{\text {stimulated sample }}-\mathrm{OD}_{\text {me- }}\right.$ dium control $\left.1 / \mathrm{OD}_{\text {positive control }} \times 100\right]$. IFN- $\gamma$ positive bovine activated plasma for positive control were obtained from the manufacturer.

\section{Estimation of quantity and quality of fecal STEC shedding}

Approximately $10 \mathrm{~g}$ of fecal matter per animal was obtained directly from rectal lumen using sterile gloved

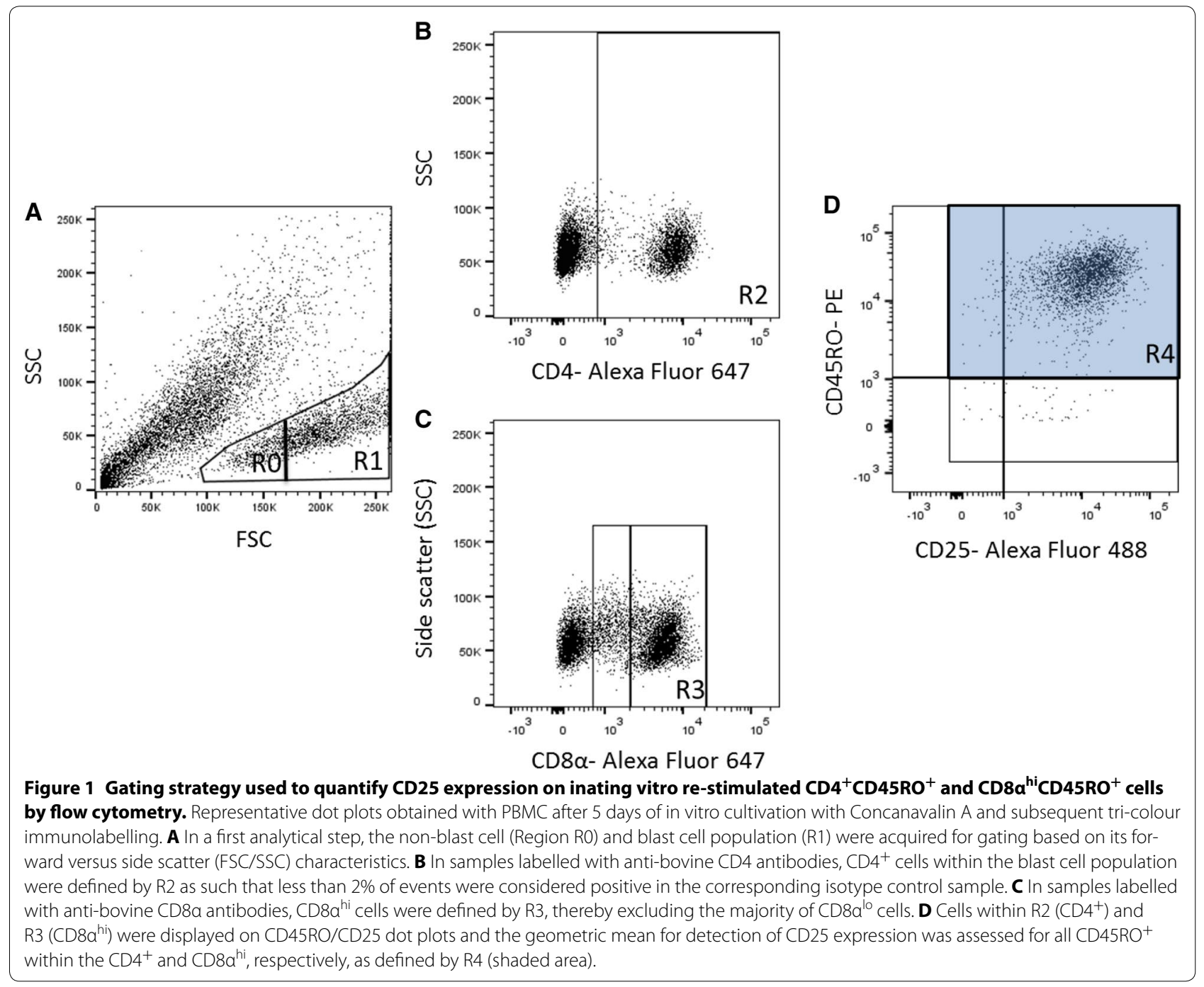


fingers and stored at $-80{ }^{\circ} \mathrm{C}$. One gram was diluted in $9 \mathrm{~mL}$ sterile PBS buffer, homogenized, $\log _{10}$ diluted over five steps, and plated on Gassner agar (SIFIN diagnostics $\mathrm{GmbH}$, Berlin, Germany). After incubation $\left(18 \mathrm{~h}, 37^{\circ} \mathrm{C}\right)$, representative agar plates were enumerated and $\mathrm{cfu} / \mathrm{g}$ feces calculated. All coliform colonies from one $10^{-1}$ dilution plate were washed off with $1 \mathrm{~mL} \mathrm{LB}$ broth supplemented with $30 \%$ glycerin, boiled $10 \mathrm{~min}$ at $100{ }^{\circ} \mathrm{C}$, put on ice for $5 \mathrm{~min}$ and used as PCR template. E. coli strain EDL933 (kindly provided by Prof. R. Bauerfeind, Institute for Hygiene and Infectious Diseases of Animals, Justus Liebig University Giessen, Germany), positive for $s t x_{1}$ and $s t x_{2}$, served as a positive control. PCR primer pairs for detection of $s t x_{1}$ and $s t x_{2}$ were designed with reference to published sequence data [37]. The detection limit was determined to be $1 \times 10^{4} \mathrm{cfu} / \mathrm{g}$ feces when two stx-negative fecal samples were spiked with $10^{-1}$ to $10^{5}$ $\mathrm{cfu} / \mathrm{g}$ feces of viable $E$. coli EDL933 bacteria.

Stx-negative samples were excluded from further analysis. Colonies from stx-positive samples (stx $x_{1}$ - and/ or $s t x_{2}$-positive) were isolated by DNA-DNA colony hybridization as described by Geue et al. [13] with the following variations. DNA probes were labeled with digoxigenin with MP4/MP3 primers [37] using the PCR DIG Probe Synthesis Kit (Roche, Deutschland Holding $\mathrm{GmbH}$, Grenzach Wyhlen, Germany) as specified by the manufacturer. Each $s t x$-positive signal was assigned to a colony and up to 10 stx-positive colonies per blot were individually cultured in $200 \mu \mathrm{L} \mathrm{LB}$ broth, incubated $(18 \mathrm{~h}$, $37{ }^{\circ} \mathrm{C}$ ), $30 \%$ glycerin added, and stored at $-80{ }^{\circ} \mathrm{C}$. The number of total stx-positive colonies on each blot was counted and cfu STEC/g feces calculated. Samples with stx-positive culture but no STEC detection by colony blot were given arbitrary STEC cfu/g feces of half of the dilution step used for blotting.

STEC isolates were characterized as to their possession of four virulence markers by multiplex PCR specific for $s t x_{1}$ and stx $x_{2}$ [37], eae [38], ehxA (=EHEC hlyA) [39]. Profiles were defined by the presence of $e a e$ and/or $e h x A$ in addition to $s t x_{1}$ and/or $s t x_{2}$. The numbers of different STEC profiles detectable in single fecal samples were recorded.

\section{Statistical analysis}

Statistical analysis was done with "IBM SPSS statistics" (version 19, IBM Corporation, New York, USA) and XLSTAT-Pro (version 2015.1. Addinsoft, Paris, France). Fisher's exact test was used to compare the PCR result of fecal stx status between the groups and to analyze if specific st $x$ types detected in fecal cultures were differently distributed among trial groups. Friedman test was used to validate development of $E$. coli $\mathrm{cfu}$ and STEC cfu over time. Dunn's test after a Kruskal-Wallis test and
Mann-Whitney U test was performed for group comparison of $E$. coli cfu, STEC cfu, anti-Stx titer, INF- $\gamma$ production and PBMC stimulation assay. Changes over time in anti-Stx titer were performed by Wilcoxon test. A value of $p<0.05$ was considered statistically significant.

\section{Results}

\section{Anti-Stx 1 and anti-Stx 2 titers in calf sera after passive and active immunization}

Stx1- and Stx2-neutralizing antibodies (nStx1Ab/ $\mathrm{nStx} 2 \mathrm{Ab}$ ) were detectable in pre-colostral sera of 2 of 9 tested VAC + and 3 of 14 tested VAC - calves (Figure 2). After colostrum intake, nStx $1 \mathrm{Ab}$ and nStx2Ab titers started to differ significantly between the $\mathrm{VAC}+$ and the $\mathrm{VAC}$ - group. The nStx $2 \mathrm{Ab}$ titer in 21 of $24 \mathrm{VAC}-$ animals even remained below the detection limit. Regardless of vit $\mathrm{E}$ supplementation, the $\mathrm{nStx} 1 \mathrm{Ab}$ and $\mathrm{nStx} 2 \mathrm{Ab}$ serum titers continued to differ significantly between the $\mathrm{VAC}+$ and the VAC - groups until $16^{\text {th }}$ week of life.

The $\mathrm{nStx} 1 \mathrm{Ab}$ titer declined within the first 11 weeks in both groups (Figure 2A). In the VAC- group, nStx1 Ab titers dropped below the detection limit in the $11^{\text {th }}$ week. In the $16^{\text {th }}$ week, most VAC- animals underwent a $\mathrm{nStx} 1 \mathrm{Ab}$ seroconversion with titers peaking in week 26. VAC+ animals showed a similar trend with clearly detectable nStx1Ab titers throughout and a slight increase from week 16 to week 26 . nStx1 Ab titers declined in both groups from week 26 to week 55 . The feeding with standard ("moderate") or elevated ("high") amounts of vit $\mathrm{E}$ had no influence on nStx1 Ab titers, except within the VAC - group in the $16^{\text {th }}$ week. nStx $1 \mathrm{Ab}$ titers had increased significantly to levels indistinguishable from titers of VAC + animals in the $\mathrm{VAC}-\mathrm{VitE}_{\mathrm{M}}$ sub-group ( 9 of 13 animals seroconverted) but not in the $\mathrm{VAC}-\mathrm{Vit}_{\mathrm{H}}$ sub-group (9 of 11 seroconverted).

Independent of vit $\mathrm{E}$ supplementation, maternal $\mathrm{nStx} 2 \mathrm{Ab}$ titers in VAC+ animals had already declined until week 3. Application of the vaccines between week 3 and 11 led to a clear increase in nStx2Ab titers, which only lasted until week 16 , however. VAC- animals had very low to undetectable levels of $\mathrm{nStx} 2 \mathrm{Ab}$ from week 11 onwards.

\section{IFN- $\gamma$ production by $\mathrm{PBMC}$ after in vitro stimulation}

PBMC isolated from calves in the $16^{\text {th }}$ week of life secreted IFN- $\gamma$ in higher amounts upon $24 \mathrm{~h}$ stimulation with ConA than PBMC in the medium control. Thereof, PBMC from $V_{i t} E_{H}$ animals produced and secreted more IFN- $\gamma$ than PBMC from VitE $_{M}$ animals irrespective of $\mathrm{rStx}_{\mathrm{MUT}}$ vaccination (Figure 3). Cultivation with lysates from $s t x$-negative $E$. coli strains previously isolated from the farm, or with rStx $1_{\text {MUT }}$ or rStx $2_{\text {MUT }}$ did not induce significantly increased IFN- $\gamma$ secretion by PBMC from 


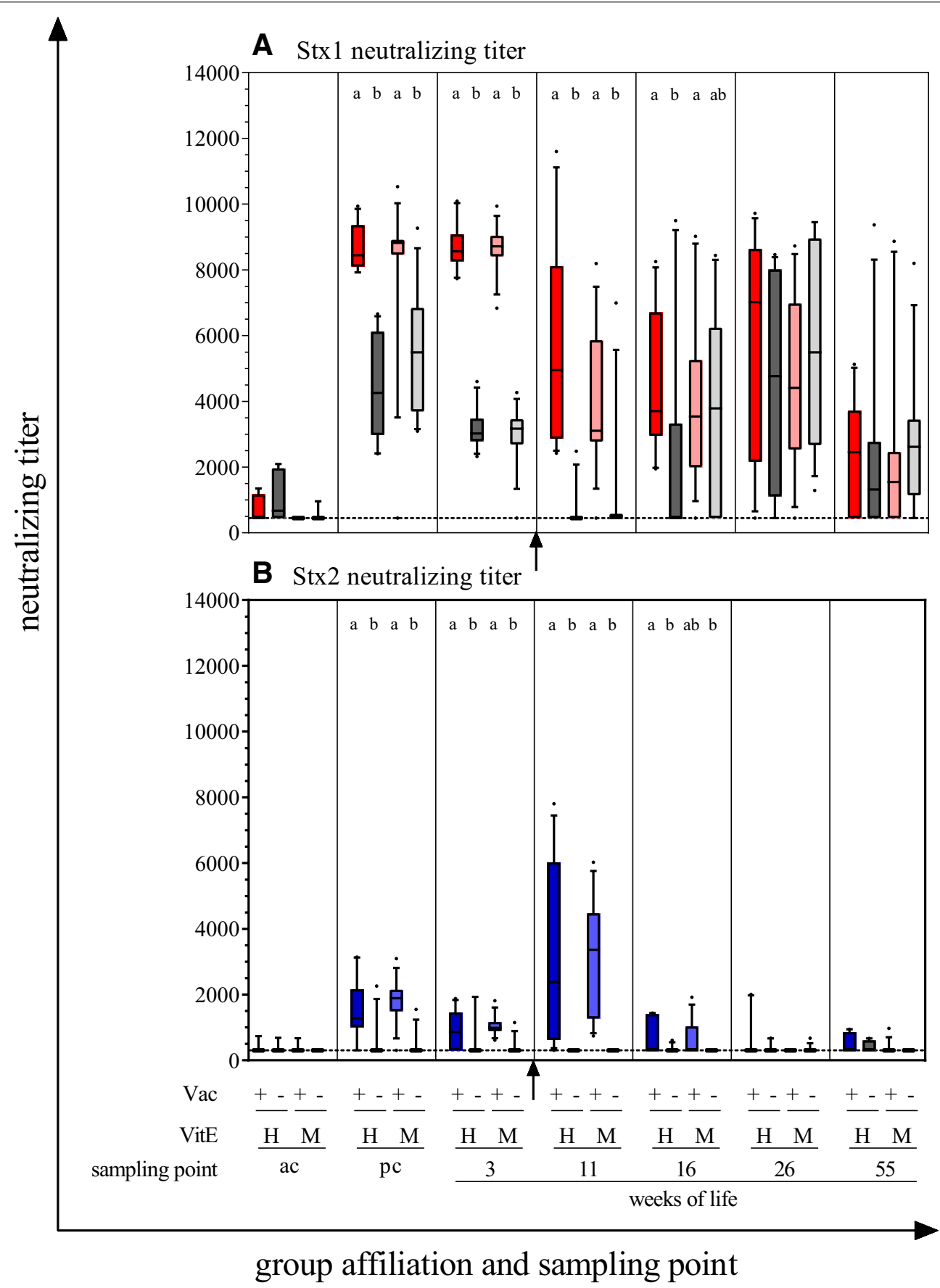

Figure 2 Temporal pattern of Stx neutralizing titers in calves' sera. Antibody titers were determined before (ac $=$ ante colostrum) and after ( $p c=$ post-colostral) colostrum intake as well as in the $3^{\text {rd }}, 11^{\text {th }}, 16^{\text {th }}, 26^{\text {th }}$ and $55^{\text {th }}$ week of life. Animals were grouped according to their vaccination status $\left(\mathrm{VAC}+=\mathrm{rStX}_{\mathrm{MUT}}\right.$-Vaccinated; $\mathrm{VAC}-=$ placebo control) and the supplementation of vitamin $\mathrm{E}\left(\mathrm{Vit}_{\mathrm{H}}=\right.$ high supplementation; VitE $_{\mathrm{M}}=$ moderate supplementation). Arrows indicate active vaccination in the $5^{\text {th }}$ and $8^{\text {th }}$ week of life. A Temporal pattern of Stx 1 neutralizing titers. A titer of 450 was attributed to those samples with a relative cell activity $<30 \%$ (detection limit, dashed line). B Temporal pattern of Stx2 neutralizing titers. A titer of 300 was attributed to those samples with a relative cell activity $<20 \%$ (detection limit, dashed line). Results of Vero cell neutralization assay expressed as box plots with 5-95\% interquartile ranges. Different letters indicate significant differences between the groups at each time point separately based on Dunn's test after a Kruskal-Wallis test. 
animals of all groups. After cultivation with stx $x_{1}$-positive $E$. coli strain lysates, IFN- $\gamma$ concentrations even tended to decrease in PBMC supernatants of the $\mathrm{VitE}_{\mathrm{M}}$ fed animals compared to $\mathrm{Vit}_{\mathrm{H}}$ fed animals. Differences reached statistical significance after stimulation with $E$. coli strain 5 .

\section{CD25 expression on $\mathrm{CD} 4{ }^{+} \mathrm{CD} 45 \mathrm{RO}^{+}$and $\mathrm{CD} 8 \mathrm{a}^{\mathrm{hi}} \mathrm{CD} 45 \mathrm{RO}^{+}$ cells after in vitro stimulation}

$\mathrm{CD}^{+}{ }^{+} \mathrm{CD} 45 \mathrm{RO}^{+}$and $\mathrm{CD} 8 \alpha^{\mathrm{hi}} \mathrm{CD} 45 \mathrm{RO}^{+}$cells responses to ConA, rStx1 $1_{\text {MUT }}$ or Listeria strain lysates did not differ between calves of the VAC+ and the VAC- group (Figure 4). In contrast, cells obtained from VAC+ animals 8 weeks after vaccination $\left(16^{\text {th }}\right.$ week of life) responded to $\mathrm{rStx} 2_{\mathrm{MUT}}$ re-stimulation in vitro with an increase in the number of CD25 molecules on the cellular surface, whereas $\mathrm{CD} 25$ expression on $\mathrm{CD} 4{ }^{+} \mathrm{CD} 45 \mathrm{RO}^{+}$and $\mathrm{CD} 8 \alpha^{\text {hi }} \mathrm{CD} 45 \mathrm{RO}^{+}$of VAC- animals was indistinguishable from that of cells in the medium control. The effect of vaccination was significant for $\mathrm{CD} 4^{+} \mathrm{CD} 45 \mathrm{RO}^{+}$from VitE $_{\mathrm{H}}$ and $\mathrm{VitE}_{\mathrm{M}}$ animals, but for $\mathrm{CD} 8 \alpha^{\text {hi }} \mathrm{CD} 45 \mathrm{RO}^{+}$cells in the $\mathrm{VitE}_{\mathrm{M}}$ group only. Such an effect of $\mathrm{rStx} 2_{\mathrm{MUT}}$ restimulation on $\mathrm{CD} 25$ expression by $\mathrm{CD} 8 \alpha^{\text {hi }} \mathrm{CD} 45 \mathrm{RO}^{+}$ cells was also observed with PBMC obtained in the $26^{\text {th }}$ week but did not reach significant levels. Incubation with lysates of 1 out of 5 E. coli strains isolated from the herd (E. coli 1 ) did not affect CD25 expression (Figure 5). Even though group differences did not always reach significant levels, $\mathrm{CD} 4{ }^{+} \mathrm{CD} 45 \mathrm{RO}^{+}$and $\mathrm{CD} 8 \alpha^{\text {hi }} \mathrm{CD} 45 \mathrm{RO}^{+}$cells of $\mathrm{VAC}+$ animals responded to lysates from the other 4 E. coli isolates with CD25 up-regulation, while respective cells from VAC - animals did not. Differences in responsiveness occurred in week 16 , but not in week 26 and were more often significantly different in the $\mathrm{VitE}_{\mathrm{M}}$ as in the $\mathrm{VitE}_{\mathrm{H}}$ group.

\section{Fecal cultures and $s t x_{1}-/ s x_{2}-P C R$}

Coliform colony-forming units per gram feces (cfu/g) in samples collected in the $3^{\text {rd }}$ week of life (median with $95 \%$ interquartile range: $\left.3.3 \times 10^{6}\left[1.3 \times 10^{6}-9.0 \times 10^{6}\right]\right)$ were significantly higher $(p<0.001)$ than in samples from the $16^{\text {th }}\left(1.1 \times 10^{5}\left[4.1 \times 10^{4}-2.6 \times 10^{5}\right]\right), 26^{\text {th }}\left(1.4 \times 10^{5}\right.$ $\left.\left[7.7 \times 10^{4}-2.6 \times 10^{5}\right]\right)$, or $55^{\text {th }}\left(4.0 \times 10^{4}\left[3.5 \times 10^{3}-\right.\right.$ $\left.\left.8.0 \times 10^{4}\right]\right)$ week of life independent of group affiliation (Additional file 2).

In an attempt to unveil potential qualitative and quantitative changes in STEC shedding resulting from Stx toxoid vaccination, quantification of shedding as well as isolation and characterization of strains was conducted by applying an analytical workflow based on (i) detection of $s t x$ genes in the feces, (ii) stx-specific colony blotting, isolation and quantification of signal-positive colonies, and (iii) characterization of STEC isolates by multiplex PCR (see subsequent paragraph).

Taking into account all samples from VAC $+(n=95)$ and VAC- calves $(n=96)$ over time, significantly $(p=0.040)$ less fecal samples collected from VAC+ animals were stx-positive by PCR than samples from VAC - animals (32/95 [33.7\%] versus 47/96 [49.0\%] samples in the VAC+ and the VAC- group, respectively). At each individual sampling point, less samples isolated

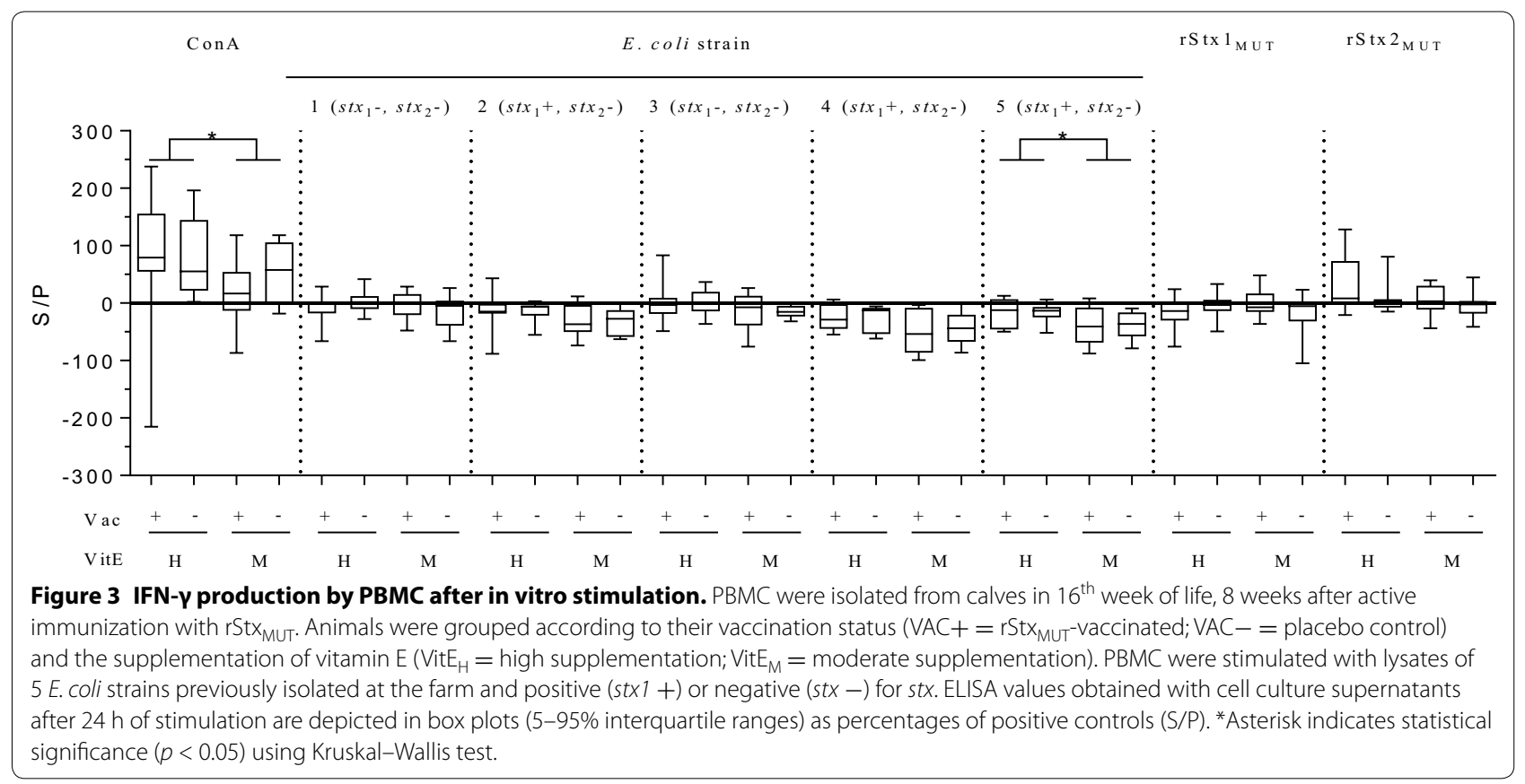




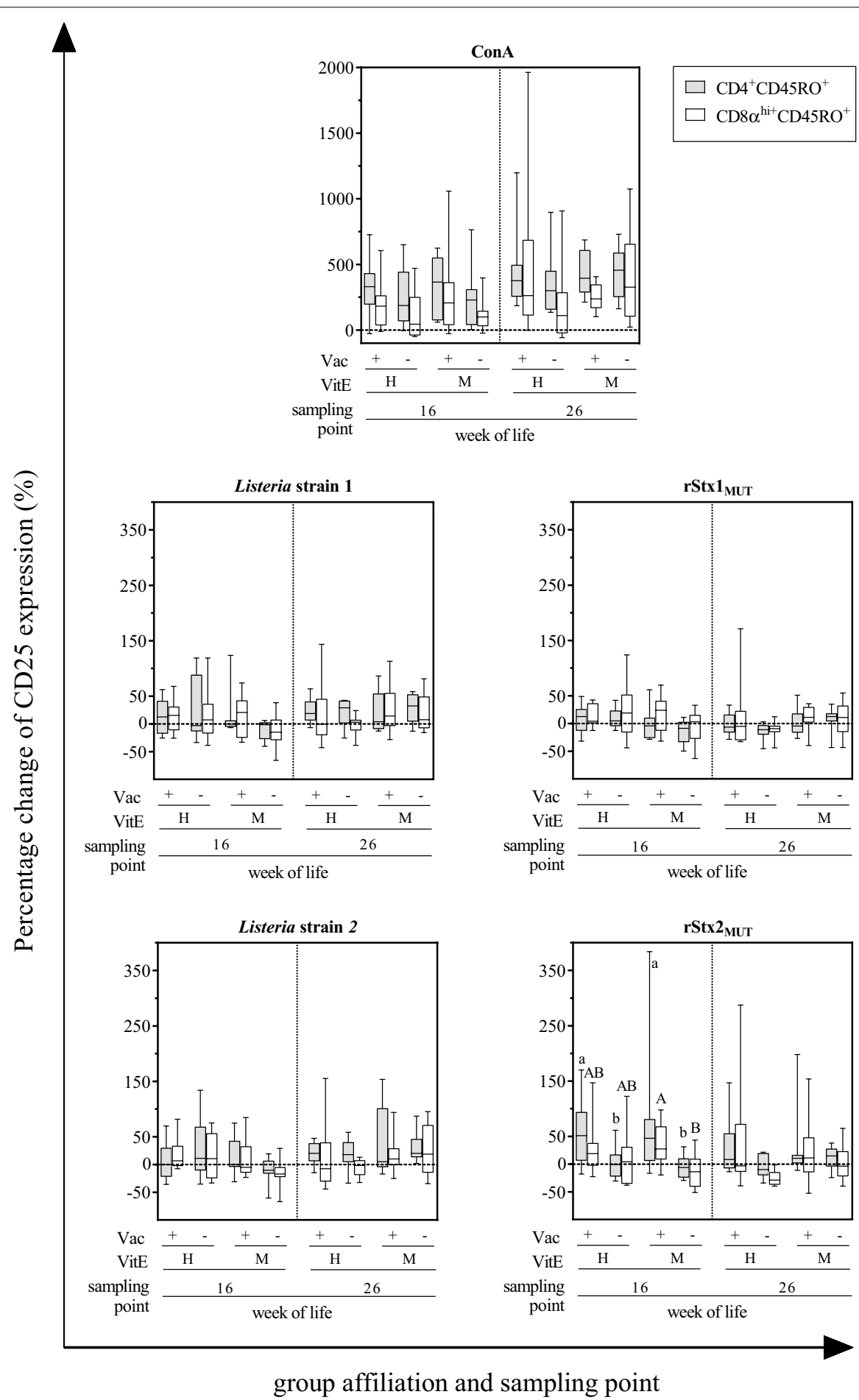

Figure 4 Expression of $\mathrm{CD} 25$ on $\mathrm{CD} 4{ }^{+} \mathrm{CD} 45 \mathrm{RO}^{+}$and $\mathrm{CD} 8 \mathrm{a}^{\text {hi }} \mathrm{CD} 45 \mathrm{RO}^{+}$cells after cultivation with ConA, Shiga toxoids or Listeria monocytogenes lysates. PBMC were isolated from calves in their $16^{\text {th }}$ and $26^{\text {th }}$ week of life, corresponding 8 and 18 weeks after active immunization with $r S t x_{M U T}$. Animals were grouped according to their vaccination status $\left(V A C+=r S t x_{M U T}-\right.$ vaccinated; $V A C-=$ placebo control) and the supplementation of vitamin $\mathrm{E}\left(\mathrm{VitE}_{\mathrm{H}}=\right.$ high supplementation; $\mathrm{Vit}_{\mathrm{M}}=$ moderate supplementation). Data obtained by flow cytometric analysis of the PBMC cultures after 5 days cultivation is depicted in box plots (5-95\% interquartile ranges) as change of the geometric mean of fluorescence intensity of $\mathrm{CD} 25$ on $\mathrm{CD}_{4}^{+}{ }^{+} \mathrm{CD} 45 \mathrm{RO}^{+}$and $\mathrm{CD} 8 \mathrm{a}^{\text {hi }} \mathrm{CD} 45 \mathrm{RO}^{+}$relative to unstimulated control cells (the latter values defined as 0 , indicated by the dashed line). Different letters indicate significant differences between the groups in $\mathrm{CD} 4{ }^{+} \mathrm{CD} 45 \mathrm{RO} \mathrm{O}^{+}$(lower case letters) and $\mathrm{CD} 8 \mathrm{a}^{\text {hi }} \mathrm{CD} 45 \mathrm{RO}^{+}$(capital letters) cells ( $p<0.05$, Kruskal-Wallis test with post hoc Dunn's test). 


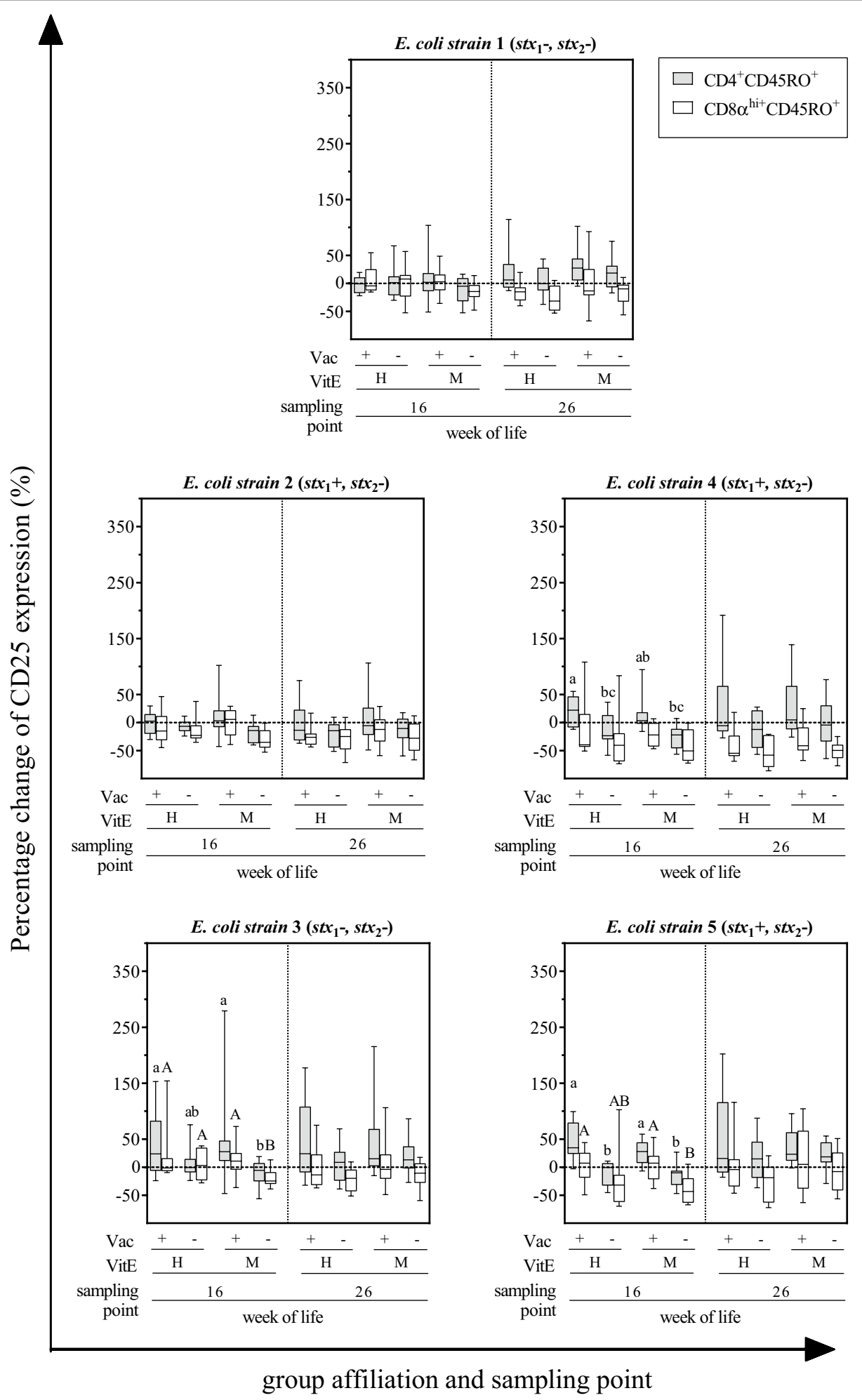

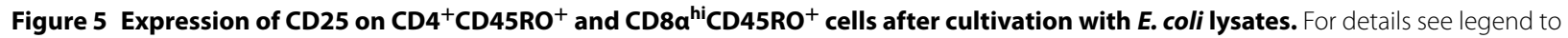
Figure 4. 
from VAC + animals were positive for stx-specific DNA than samples from VAC- animals, but those differences did not reach statistical significance (Figure 6A). The level of vit $\mathrm{E}$ supplementation did not influence the frequency of stx-positive fecal samples on its own. However, significant $(p=0.017)$ less samples collected from $\mathrm{VAC}+\mathrm{VitE}_{\mathrm{M}}$ animals $(16 / 52$ [30.8\%]) were $s t x$-positive than from $\mathrm{VAC}-\mathrm{VitE}_{\mathrm{M}}$ animals (29/52 [55.8\%]) over the whole observation period. In contrast, samples from $\mathrm{VAC}+\mathrm{VitE}_{\mathrm{H}}$ (16 stx-positive of 43 [37.2\%]) and from $\mathrm{VAC}-\mathrm{VitE}_{\mathrm{H}}(18 / 44$ [40.9\%]) animals did not differ significantly $(p=0.827)$. Three and two animals in the VAC+ and the VAC-group remained st $x$-negative, respectively, throughout the entire observation study. All other animals shed STEC, as deduced from a positive PCR result for $s t x_{1}$ or $s t x_{2}$, at least on one occasion. It cannot be ruled out that single PCR-positive fecal samples result from passaging of the bacteria rather than true infection. As a proxy of infection, 7 and 14 animals in the VAC+ and in the VAC - group, respectively, were found to be fecal-positive for at least one toxin type on at least two consecutive sampling times. Again, the $\mathrm{VitE}_{\mathrm{H}}$ and $\mathrm{VitE}_{\mathrm{M}}$ groups differed in their STEC shedding pattern. The number of animals that remained stx-negative were evenly distributed $\left(\mathrm{VAC}+\mathrm{Vit}_{\mathrm{H}}: 1 / 11, \mathrm{VAC}-\mathrm{Vit}_{\mathrm{H}}\right.$ : 2/13; $\left.\mathrm{VAC}+\mathrm{VitE}_{\mathrm{M}}: 1 / 11 ; \mathrm{VAC}-\mathrm{VitE}_{\mathrm{M}}: 1 / 13\right)$. However, 10 calves in the $\mathrm{VAC}-\mathrm{VitE}_{\mathrm{M}}$ group but only 5,2 and 4 calves in the $\mathrm{VAC}+\mathrm{Vit}_{\mathrm{H}}$, the $\mathrm{VAC}-\mathrm{VitE}_{\mathrm{H}}$ and the $\mathrm{VAC}+\mathrm{VitE}_{\mathrm{M}}$ groups, respectively, were fecal-positive for $s t x$ on at least two consecutive sampling times (Additional file 1).

Considering stx-positive fecal samples only, such samples from VAC + animals contained significantly $(p=0.003)$ more often $s t x_{1}$ plus $s t x_{2}(14 / 32 ; 43.8 \%)$ than

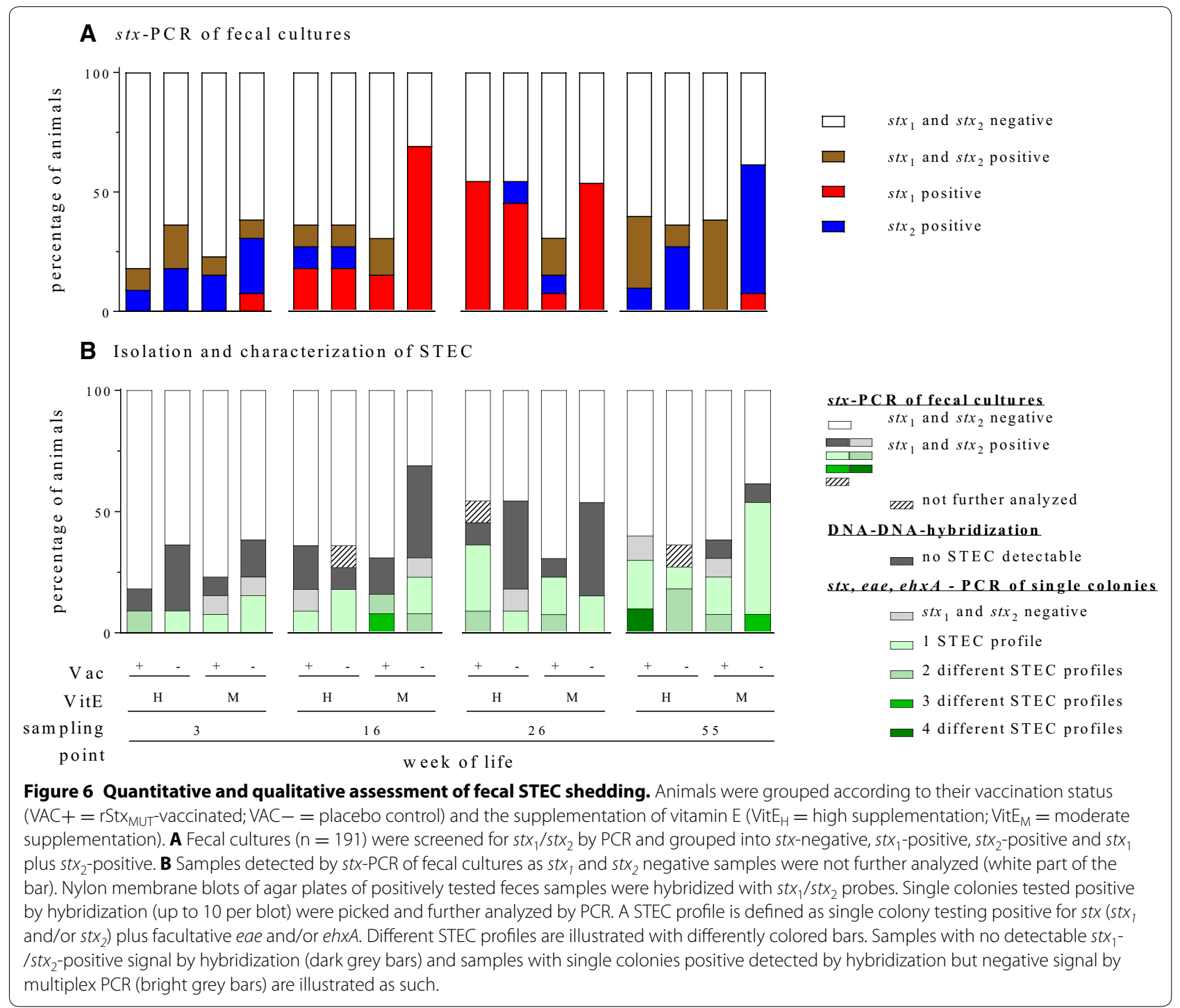


samples from VAC - animals $(6 / 47 ; 12.8 \%$; Figure $6 \mathrm{~B})$. In turn, single $s t x_{1}$ - or single $s t x_{2}$-positive samples were detected more often in VAC - (27/47 [51.1\%] and 17/47 [36.2\%], respectively) than in VAC+ $(11 / 32$ [34.4\%] and $7 / 32$ [21.9\%], respectively) animals but differences did not reach statistical different levels $(p \geq 0.171)$. STEC shedding significantly varied with vit $E$ supplementation also. A greater proportion of fecal samples from $\mathrm{VAC}+\mathrm{VitE}_{\mathrm{M}}$ animals was $s t x_{1} / s t x_{2}$-positive $(11 / 16 ; 68.8 \%)$ compared to $\mathrm{VAC}+\mathrm{VitE}_{\mathrm{H}}(3 / 16 ; 18.8 \% ; p=0.011), \mathrm{VAC}-\mathrm{VitE}_{\mathrm{H}}$ $(4 / 28 ; 22.2 \% ; p=0.014)$, and $\mathrm{VAC}-\mathrm{VitE}_{\mathrm{M}}(2 / 29 ; 6.9 \%$; $p<0.001)$. In contrast, significantly $(p=0.013)$ less fecal samples were single $s t x_{1}$-positive $(3 / 16)$ in the $\mathrm{VAC}+\mathrm{VitE}_{\mathrm{M}}$ group compared to the $\mathrm{VAC}-\mathrm{VitE}_{\mathrm{M}}$ $(17 / 29 ; 18.8 \%$ versus $58.6 \%)$ group. For individual pattern of $s t x$-positive fecal cultures see Additional file 1.

\section{Isolation and characterization of STEC strains}

The percentage of stx PCR-positive fecal samples of which the subsequently conducted colony blotting did not yield a positive signal was different between the $\mathrm{VAC}+(29.0 \%)$ and the VAC- groups (46.7\%). STEC cfu per $\mathrm{g}$ of $s t x$ PCR-positive fecal samples did not differ $(p=0.216)$ between the trial groups over the entire observation period (Additional file 2). From a total of 40 fecal samples, that had at least one positive signal on the colony blot, 215 single colonies (VAC $+n=108$, VAC $-n=107$ colonies) were analyzed to assess their virulence gene profile in order to assess possible implications of the vaccination for the composition and zoonotic potential of the STEC strains shed. As a result, isolates could be grouped into 12 virulence gene profiles based on the possession of $s t x_{1}, s t x_{2}$, eae or ehxA. Continuing with only one strain per virulence gene profile within a single sample, 64 individual STEC isolates were further analyzed (Table 1). More stx $x_{1}$-positive isolates were also positive for eae (59.1\%) than $s t x_{2}$ - and $s t x_{1} / s t x_{2}-$ positive isolates (28.0 and $28.6 \%$ ). The $e h x A$ gene was detected in $77.3 \%$ of $s t x_{1}-, 84.0 \%$ of $s t x_{2}-$ and $28.6 \%$ of $s t x_{1}-/ s t x_{2}$-positive isolates. Ten isolates lost the $s t x$ gene upon sub-culturing as they were originally positive by colony blot. The relative number of stx-blot positive samples harbouring more than one gene profile varied between VAC + and VAC - animals (38.9 and 19.0\%, respectively) (Figure $5 \mathrm{~B}$ ), indicating that vaccination had a qualitative impact on STEC shedding.

\section{Discussion}

Up to now, experimental and licensed vaccines for reduction of STEC shedding (Econiche Corp, Belleville, Canada; Epitopix, Willmar, USA) were only partially successful and effects were mostly restricted to subpopulations of STEC, e.g. O157:H7/H- [14-16]. This proof-of-concept study provides first evidence that immunization with Stx toxoid-based vaccines under field-like conditions enables calves to actively mount a more effective immune response against STEC strains circulating in the cohort. Observed effects of $\mathrm{rStx}_{\mathrm{MUT}}$

Table 1 Occurrence of individual STEC gene profiles in fecal samples

\begin{tabular}{|c|c|c|c|c|c|}
\hline \multirow[t]{2}{*}{ STEC gene profiles } & \multicolumn{5}{|c|}{ Number of STEC profiles per group } \\
\hline & $\mathrm{VAC}+\mathrm{VitE}_{\mathrm{H}}$ & $\mathrm{VAC}-\mathrm{VitE}_{\mathrm{H}}$ & $\mathrm{VAC}+\mathrm{VitE}_{\mathrm{M}}$ & $\mathrm{VAC}-\mathrm{VitE}_{\mathrm{M}}$ & Total \\
\hline$s t x_{1}$ & 1 & 0 & 1 & 1 & 3 \\
\hline$s t x_{1}$, eae & 1 & 1 & 0 & 0 & 2 \\
\hline stx $x_{1}, \operatorname{eh} \times A$ & 2 & 0 & 2 & 2 & 6 \\
\hline stx, eae, ehxA & 3 & 1 & 3 & 4 & 11 \\
\hline$s t x_{2}$ & 0 & 0 & 0 & 2 & 2 \\
\hline stx ${ }_{2}$, eae & 0 & 0 & 1 & 1 & 2 \\
\hline $\operatorname{stx}_{2}, e h x A$ & 3 & 3 & 5 & 5 & 16 \\
\hline stx ${ }_{2}$, eae, ehxA & 1 & 2 & 1 & 1 & 5 \\
\hline stx $x_{1}$, stx 2 & 1 & 1 & 1 & 1 & 4 \\
\hline$s t x_{1}, s t x_{2}, e h x A$ & 1 & 0 & 0 & 0 & 1 \\
\hline$s t x_{1}, s t x_{2}, e a e, e h x A$ & 0 & 1 & 0 & 0 & 1 \\
\hline$s t x_{1}, s t x_{2}, e h x A$ & 1 & 0 & 0 & 0 & 1 \\
\hline$e a e^{a}$ & 1 & 1 & 1 & 0 & 3 \\
\hline Negative $^{\mathrm{a}}$ & 1 & 3 & 1 & 2 & 7 \\
\hline Total & 16 & 13 & 16 & 19 & 64 \\
\hline
\end{tabular}

Fecal samples were taken over the entire observation period according to the group affiliation of the calves. Profiles were defined by the genes stx ${ }_{1}$, stx ${ }_{2}$, eae and $e h x A$ and the numbers of different STEC profiles detectable in single fecal samples were recorded, whereby isolates with the same STEC gene profile within a single fecal sample were counted once.

a All isolates were initially stx-positive as their selection was based on the detection of stx by colony hybridization. 
immunization on the incidence of stx-positive fecal samples were moderate compared to effects reportedly seen after immunization of cattle with STEC adhesins and subsequent homologous experimental challenge $[14,16]$. However, the immune response primarily analysed herein was only indirectly achieved through natural exposure to a bacterial pathogen known to asymptomatically colonize the bovine intestine. Furthermore, vaccinated and control animals were kept together and participated in the same network of animal-to-animal and environmentalto-animal transitional events. The study did not include an immunological naïve control group, i.e. the colostrum pool administered to control calves was not free of anti-Stx antibodies. These confounding factors make the degree of differences in cellular immune responses and STEC shedding between animals groups highly plausible.

Colostral nStx $1 \mathrm{Ab}$ and $\mathrm{nStx} 2 \mathrm{Ab}$ were effectively transferred to calves with nStx1Ab titers clearly exceeding $\mathrm{nStx} 2 \mathrm{Ab}$ titers in the $\mathrm{VAC}+$ as well as the $\mathrm{VAC}-$ group similar to what was observed after natural Stx exposure and after $\mathrm{rStx}_{\mathrm{MUT}}$ vaccination [12, 24, 40]. Active $\mathrm{rStx}_{\mathrm{MUT}}$ immunization in week 5 and 8 did not result in a detectable increase of nStx1 Ab in calves' sera, different from calves vaccinated after vanishing of maternal antibodies [24]. High maternal titers may have impaired the success of the $\mathrm{rStx} 1_{\mathrm{MUT}}$ vaccination but a significant humoral immune response was achieved by rStx $2_{\mathrm{MUT}}$ immunization of calves with no or low serum nStx2Ab titers at the time of active vaccination. A modified vaccination scheme, consisting of maternal vaccination, prime vaccination of calves not earlier than week 11 and booster application in the second half of the first year of life might overcome these obstacles.

Applying the quantitation of CD25 expression on $\mathrm{CD}_{4} 5 \mathrm{RO}^{+}$lymphocytes for monitoring antigen-specific $\mathrm{T}$ cell responses in cattle, as suggested by Koo et al. [41], we found that peripheral $\mathrm{CD}_{4}^{+} \mathrm{CD} 45 \mathrm{RO}^{+}$and $\mathrm{CD} 8 \alpha^{\text {hi }} \mathrm{CD} 45 \mathrm{RO}^{+}$cells from VAC + calves responded better to re-stimulation with STEC antigens. Eight weeks after active vaccination, PBMCs from VAC+ animals responded more pronounced to $\mathrm{rStx} 2_{\mathrm{MUT}}$ re-stimulation in vitro suggesting that vaccination directly induced an adaptive immune response against Stx2. The missing $\mathrm{T}$ cell responsiveness to $\mathrm{rStx}_{\mathrm{MUT}}$ in vitro may result from high maternal humoral protection at the time of active vaccination as discussed for the humoral response. Of note, VAC + calves were capable of mounting an earlier adaptive immune response to $E$. coli antigens other than Stx 1 as well. This became apparent by re-stimulation with $s t x_{1}+/ s t x_{2}-E$. coli lysates in the $16^{\text {th }}$ week of life. The $\mathrm{CD}_{4}^{+}$subset analysed may have comprised different $T_{H}$ subsets as well as $T_{\text {reg }}$ cells. Bovine NK cells express CD45RO, CD8 $\alpha \alpha$ and $\mathrm{CD} 8 \alpha \beta$ [42] and are able to respond to bacterial molecular patterns without $\mathrm{MHC}$ restriction [43-45]. By gating on CD8 $\alpha^{\text {hi }}$ cells, we aimed at excluding $\mathrm{NK}$ as well as $\gamma \delta \mathrm{T}$ cells which both may express CD8 $\alpha^{\text {lo }}[43,46]$. PBMC of the calves in the VAC+ and the VAC - group responded differently to some but not all bacterial lysates implying that the response detected was not due to an innate-like immune response but, in support of our hypothesis, indicative of an elevated adaptive cellular immune response to STEC strains circulating in the herd. Antibodies to STEC antigens may not be sufficient to protect cattle from STEC colonization [47]. Corbishley et al. showed by characterizing the epitopes recognized by $\mathrm{CD} 4^{+} \mathrm{T}$-cells that STEC-infected calves develop a specific immunological response at the infection site [48]. In light of these findings, the relative importance of functionally different immune cell populations for the control of STEC colonization in cattle's intestine urgently needs to be unveiled.

Hoffmann et al. showed that calves inoculated twice with stx-negative O157 strain, but not the calves inoculated with $s t x_{2}$-positive O157 strain, developed cellular immune responses against the latter strain [17]. Under less standardized field conditions in the current study, $\mathrm{VAC}+$ animals also responded to one of the two stx-negative $E$. coli strains better than VAC- animals, implying that $\mathrm{rStx}_{\mathrm{MUT}}$ vaccination enables calves to build an infection immunity towards other antigens that are common in STEC and other E. coli strains. In order to determine if this supportive effect expands to infections with other enteric bacterial agents, immune control of which heavily relies on cellular immune responses, we also re-stimulated PBMC of the calves with lysates of Listeria strains previously isolated on the experimental farm. A beneficial effect of $\mathrm{Stx}_{\mathrm{MUT}}$ vaccination on the immune response against Listeria monocytogenes in the cohort of calves under study could not be confirmed. We cannot rule out that this resulted from lack of exposure as we did not monitor the Listeria infection status of the calves. Nevertheless, T-cells from VAC+ animals, which we consider to have been less exposed to Stx, tended to respond more vigorously to ConA in week 16 . Stx inhibits the immunogenic effect of systemically administered antigen [49] and Kieckens et al. as well as Corbishley et al. showed that STEC colonization affect cattle's general immune response $[50,51]$ suggesting that Stx impairs immune responses in cattle in a more general manner than currently recognized.

The vaccine deployed in this study contained $\mathrm{rStx} 1_{\mathrm{MUT}}$ and $\mathrm{rStx} 2_{\mathrm{MUT}}$, respectively, but is not devoid of antigens derived from the laboratory E. coli $\mathrm{K}-12$ strain used for recombinant protein expression. The control calves were placebo injected with $\mathrm{NaCl}$ solution and adjuvant to exclude the adjuvant's influence. Registered 
O157-vaccines (Econiche Corp, Belleville, Canada; Epitopix, Willmar, USA) contain proteins from the LEE locus and/or siderophore proteins as the main vaccine component. Both potentially protective STEC antigens are not included in the genome of the E. coli $\mathrm{K}-12$ strain. Moreover, residual $E$. coli antigens other than $\mathrm{rStx}_{\mathrm{MUT}}$ and $r S t x 2_{\mathrm{MUT}}$ in the vaccine preparations are unlikely to have had an effect on the parameters assessed. Firstly, the general coliform flora in the calves was not affected by vaccination as no differences in the colony count were measured. Secondly, T-cells of VAC + calves responded to $\mathrm{rStx} 2_{\mathrm{MUT}}$ containing vaccine preparations derived from the laboratory $E$. coli $\mathrm{K}-12$ strain in vitro but not to the $\mathrm{rStx}_{\mathrm{MUT}}$ containing preparation strongly arguing against a general anti-E. coli immunity induced by the vaccination itself.

The hypothesis that high vit E supplementation stimulates the immune system and thereby supports the effect of $\mathrm{rStx}_{\mathrm{MUT}}$ vaccination to reduce STEC shedding could not be substantiated. The higher vit E supplementation had no positive effect on CD25 expression by $\mathrm{CD} 4{ }^{+} \mathrm{D} 45 \mathrm{RO}^{+}$and $\mathrm{CD} 8 \alpha^{\text {hi }} \mathrm{CD} 45 \mathrm{RO}^{+}$after stimulation with STEC and $E$. coli and rather a negative effect on STEC shedding in VAC+ calves. Nevertheless, 354 IU compared to 188 IU daily vit E supplementation via milk replacer exhibited effects on STEC shedding within the $\mathrm{VAC}+$ group for reasons that have not been unveiled yet and interactive effects of vit E supply and $\mathrm{rStx}_{\mathrm{MUT}}$ vaccination on, e.g., feed intake (N. Schmidt, T. Luhmann, L. Hüther, U. Meyer, S. A. Barth, L. Geue, C. Menge, J. Frahm, S. Dänicke, submitted for publication) have also to be taken into consideration.

Shiga toxoid immunization did not influence the absolute amount of STEC in fecal samples that still were $s t x$ PCR-positive. Moreover, our data indicate that samples from VAC+ calves tended to have higher STEC cfu in relation to total coliform counts. As the methodical workflow allowed isolation of STEC via colony blotting only from samples with STEC cfu/g feces maximally $2 \log _{10}$ levels lower than coliform flora, we assume that rStx $_{\text {MUT }}$ vaccination reduced the incidence of STEC primarily in animals with low numbers of STEC within the coliform flora rather than affecting the shedding of animals with relatively high levels of STEC shedding, referred to as supershedders [52].

Descriptive analysis of virulence gene profiles of STEC isolates showed that VAC + animals had higher number of different STEC profiles per fecal sample and that STEC strains isolated from VAC + animals were significantly more often both $s t x_{1}$ and $s t x_{2}$ positive than isolates from VAC-. The effect of $\mathrm{rStx}_{\text {MUT }}$ vaccination is mainly indirect and the success of the vaccination approach depends on sufficient exposure to a relevant number of bacteria of all strains implicated in STEC transmission dynamics in a respective cattle herd. In order to avoid selection of more virulent STEC strains by vaccination of cattle, the immunogenic capacity (dose) of the toxoids, the vaccine formulation, and the time and route of application have to be optimized and other virulence factors conserved among STEC strains like intimin [51], EspB [53] or associated with the colonization type of STEC strains [6] have to be included in the vaccine and/or the feed composition. Nevertheless, data presented here support our hypothesis that the immune modulatory effect of Stx should be considered for integration in strategies aiming at reducing STEC shedding in cattle.

\section{Additional files}

Additional file 1. Individual pattern of stx-positive fecal cultures in the $3^{\text {rd }}, 16^{\text {th }}, 26^{\text {th }}$ and $55^{\text {th }}$ week of life. Animals were grouped according to their vaccination status (VAC+ $=r_{S t x}$ MUT-vaccinated; $V A C-^{-}=$placebo control) and the supplementation of vitamin $\mathrm{E}\left(\mathrm{Vit}_{\mathrm{H}}=\right.$ high supplementation; $\mathrm{Vit}_{\mathrm{M}}=$ moderate supplementation). White boxed depict $s t x_{1}-/ s t x_{2}$-fecal cultures analyzed by multiplex PCR. Detection of $s t x_{1}$ and $s t x_{2}$ is marked in gray and black, respectively. White cross-out boxes mark a gap in sampling.

Additional file 2. Quantitative assessment of fecal E. coli and STEC shedding. Fecal E. coli colony forming units (cfu) are shown with respect to the total feces sampling pool (Shiga toxin positive and negative feces) and Shiga toxin positive pool of each trial group at each sampling.

\begin{abstract}
Abbreviations
Stx: Shiga toxin; STEC: Shiga toxin-producing Escherichia coli; $r S t x 1_{\mathrm{MUT}} / \mathrm{rStx}-$ $2_{\text {MUT: }}$ recombinant Shiga toxoids; EHEC: enterohemorrhagic Escherichia coli; Vitamin E: vit E; VNA: Vero cell neutralization assay; VAC+: rStx $_{\text {MUT }}$-vaccinated animals; VAC-: placebo-treated animals; $V_{i t} E_{H}$ : vit E high feeding group; PBMC: peripheral blood mononuclear cells; Vit $E_{M}$ : vit $E$ moderate feeding group; MR: milk replacer; DM: dry matter; VCA: Vero cell cytotoxicity assay; nAb: neutralizing antibody; cfu: colony forming units; ConA: Concanavalin A; MC: medium control; nStx1Ab/nStx2Ab: Stx1-/Stx2-neutralizing antibodies.
\end{abstract}

\section{Competing interests}

The authors declare that they have no competing interests.

\section{Authors' contributions}

CM, SD, SB and LG were involved in hypothesis generation and experimental design. NS, SB, JF, and UM were involved in organizing and conducting the experiments. CM, SB, LG, NS were involved in interpreting and analyzing the results and NS was a major contributor in writing the manuscript. All authors read and approved the final manuscript.

\section{Acknowledgements}

The authors would like to thank Prof. Dr. Rolf Bauerfeind (Justus-Liebig University Giessen, Institute for Hygiene and Infectious Diseases of Animals) for kind provision of vaccine antigen and EDL933 strain as well as the staff of the experimental facilities (Friedrich-Loeffler-Institut, Brunswick) for their support during the animal trial. We acknowledge the excellent technical support by Nicola Mickenautsch, Lara Lindner and Anke Hinsching.

\section{Availability of data and materials}

The datasets used and/or analyzed during the current study is provided in detail in the results section of the manuscript.

Consent for publication

Not applicable. 


\section{Ethics approval and consent to participate}

The study was carried out in strict accordance with German law for the care and use of experimental animals. Experiments were approved by the Lower Saxony State Office for Consumer Protection and Food Safety (LAVES), Oldenburg, Germany (Reg Number 33.9-42,502.04.12/0933 and 33.9-4250204-11/0444, vaccination and vit E treatment, respectively).

\section{Funding}

Nadine Schmidt was financial supported in part by the H. Wilhelm Schaumann foundation, Hamburg.

\section{Author details}

${ }^{1}$ Friedrich-Loeffler-Institut (FLI)/Federal Research Institute for Animal Health, Institute of Molecular Pathogenesis, Jena, Germany. ${ }^{2}$ Friedrich-Loeffler-Institut (FLI), Institute of Animal Nutrition, Brunswick, Germany. ${ }^{3}$ Justus Liebig Universität Giessen, Institute for Hygiene and Infectious Diseases of Animals, Giessen, Germany.

\section{Publisher's Note}

Springer Nature remains neutral with regard to jurisdictional claims in published maps and institutional affiliations.

Received: 21 February 2018 Accepted: 22 February 2018

Published online: 07 March 2018

\section{References}

1. EFSA (European Food Safety Authority), ECDC (European Centre for Disease Prevention and Control) (2017) The European Union summary report on trends and sources of zoonoses, zoonotic agents and foodborne outbreaks in 2016. EFS2 15:148

2. Krogfelt KA (1991) Bacterial adhesion: genetics, biogenesis, and role in pathogenesis of fimbrial adhesins of Escherichia coli. Rev Infect Dis 13:721-735

3. Jordan DM, Cornick N, Torres AG, Dean-Nystrom EA, Kaper JB, Moon HW (2004) Long polar fimbriae contribute to colonization by Escherichia coli O157:H7 in vivo. Infect Immun 72:6168-6171

4. Ackers ML, Mahon BE, Leahy E, Goode B, Damrow T, Hayes PS, Bibb WF, Rice DH, Barrett TJ, Hutwagner L, Griffin PM, Slutsker L (1998) An outbreak of Escherichia coli O157:H7 infections associated with leaf lettuce consumption. J Infect Dis 177:1588-1593

5. Barth S, Tscholshiew A, Menge C, Weiss R, Baljer G, Bauerfeind R (2007) Virulence and fitness gene patterns of Shiga toxin-encoding Escherichia coli isolated from pigs with edema disease or diarrhea in Germany. Berl Munch Tierarztl Wochenschr 120:307-316

6. Barth SA, Menge C, Eichhorn I, Semmler T, Wieler LH, Pickard D, Belka A, Berens C, Geue $L$ (2016) The accessory genome of Shiga toxin-producing Escherichia coli defines a persistent colonization type in cattle. Appl Environ Microbiol 82:5455-5464

7. Hussein HS, Sakuma T (2005) Prevalence of shiga toxin-producing Escherichia coli in dairy cattle and their products. J Dairy Sci 88:450-465

8. Menrath A, Wieler LH, Heidemanns K, Semmler T, Fruth A, Kemper N (2010) Shiga toxin producing Escherichia coli: identification of nonO157:H7-Super-Shedding cows and related risk factors. Gut Pathog 2:7

9. Hamm K, Barth SA, Stalb S, Geue L, Liebler-Tenorio E, Teifke JP, Lange E, Tauscher K, Kotterba G, Bielaszewska M, Karch H, Menge C (2016) Experimental infection of calves with Escherichia coli O104:H4 outbreak strain. Sci Rep 6:32812

10. Naylor SW, Gally DL, Low JC (2005) Enterohaemorrhagic E. coli in veterinary medicine. Int J Med Microbiol 295:419-441

11. Caprioli A, Morabito S, Brugere H, Oswald E (2005) Enterohaemorrhagic Escherichia coli: emerging issues on virulence and modes of transmission. Vet Res 36:289-311

12. Fröhlich J, Baljer G, Menge C (2009) Maternally and naturally acquired antibodies to Shiga toxins in a cohort of calves shedding Shiga-toxigenic Escherichia coli. Appl Environ Microbiol 75:3695-3704

13. Geue L, Segura-Alvarez M, Conraths FJ, Kuczius T, Bockemuhl J, Karch $H$, Gallien P (2002) A long-term study on the prevalence of shiga toxin-producing Escherichia coli (STEC) on four German cattle farms. Epidemiol Infect 129:173-185

14. Vande Walle K, Vanrompay D, Cox E (2013) Bovine innate and adaptive immune responses against Escherichia coli O157:H7 and vaccination strategies to reduce faecal shedding in ruminants. Vet Immunol Immunopathol 152:109-120

15. Callaway TR, Anderson RC, Edrington TS, Genovese KJ, Harvey RB, Poole TL, Nisbet DJ (2004) Recent pre-harvest supplementation strategies to reduce carriage and shedding of zoonotic enteric bacterial pathogens in food animals. Anim Health Res Rev 5:35-47

16. Snedeker KG, Campbell M, Sargeant JM (2012) A systematic review of vaccinations to reduce the shedding of Escherichia coli 0157 in the faeces of domestic ruminants. Zoonoses Public Health 59:126-138

17. Hoffman MA, Menge C, Casey TA, Laegreid W, Bosworth BT, DeanNystrom EA (2006) Bovine immune response to Shiga-toxigenic Escherichia coli O157: H7. Clin Vaccine Immunol 13:1322-1327

18. Stamm I, Mohr M, Bridger PS, Schropfer E, Konig M, Stoffregen WC, DeanNystrom EA, Baljer G, Menge C (2008) Epithelial and mesenchymal cells in the bovine colonic mucosa differ in their responsiveness to Escherichia coli Shiga toxin 1. Infect Immun 76:5381-5391

19. Moussay E, Stamm I, Taubert A, Baljer G, Menge C (2006) Escherichia coli Shiga toxin 1 enhances il-4 transcripts in bovine ileal intraepithelial lymphocytes. Vet Immunol Immunopathol 113:367-382

20. Menge C, Wieler LH, Schlapp T, Baljer G (1999) Shiga toxin 1 from Escherichia coli blocks activation and proliferation of bovine lymphocyte subpopulations in vitro. Infect Immun 67:2209-2217

21. Menge C, Stamm I, van Diemen PM, Sopp P, Baljer G, Wallis TS, Stevens MP (2004) Phenotypic and functional characterization of intraepithelial lymphocytes in a bovine ligated intestinal loop model of enterohaemorrhagic Escherichia coli infection. J Med Microbiol 53:573-579

22. Menge C, Stamm I, Wuhrer M, Geyer R, Wieler LH, Baljer G (2001) Globotriaosylceramide (Gb(3)/CD77) is synthesized and surface expressed by bovine lymphocytes upon activation in vitro. Vet Immunol Immunopathol 83:19-36

23. Stamm I, Wuhrer M, Geyer R, Baljer G, Menge C (2002) Bovine lymphocytes express functional receptors for Escherichia coli Shiga toxin 1. Microb Pathog 33:251-264

24. Kerner K, Bridger PS, Kopf G, Frohlich J, Barth S, Willems H, Bauerfeind $\mathrm{R}$, Baljer G, Menge C (2015) Evaluation of biological safety in vitro and immunogenicity in vivo of recombinant Escherichia coli Shiga toxoids as candidate vaccines in cattle. Vet Res 46:38

25. Hovde CJ, Calderwood SB, Mekalanos JJ, Collier RJ (1988) Evidence that glutamic acid 167 is an active-site residue of Shiga-like toxin I. Proc Natl Acad Sci U S A 85:2568-2572

26. Yamasaki S, Furutani M, Ito K, Igarashi K, Nishibuchi M, Takeda Y (1991) Importance of arginine at position 170 of the A subunit of Vero toxin 1 produced by enterohemorrhagic Escherichia coli for toxin activity. Microb Pathog 11:1-9

27. Oanh TKN, Nguyen VK, de Greve H, Goddeeris BM, Urban JF (2011) Protection of piglets against Edema disease by maternal immunization with Stx2e toxoid. Infect Immun 80:469-473

28. Makino S, Watarai M, Tabuchi H, Shirahata T, Furuoka H, Kobayashi Y, Takeda Y (2001) Genetically modified Shiga toxin 2e (Stx2e) producing Escherichia coli is a vaccine candidate for porcine edema disease. Microb Pathog 31:1-8

29. Ohmura-Hoshino M, Yamamoto M, Yuki Y, Takeda Y, Kiyono H (2004) Nontoxic Stx derivatives from Escherichia coli possess adjuvant activity for mucosal immunity. Vaccine 22:3751-3761

30. Ishikawa S, Kawahara K, Kagami Y, Isshiki Y, Kaneko A, Matsui H, Okada N, Danbara H (2003) Protection against Shiga toxin 1 challenge by immunization of mice with purified mutant Shiga toxin 1. Infect Immun 71:3235-3239

31. Reddy PG, Morrill JL, Frey RA (1987) Vitamin E requirements of dairy calves. J Dairy Sci 70:123-129

32. Reddy PG, Morrill JL, Minocha HC, Stevenson JS (1987) Vitamin E is immunostimulatory in calves. J Dairy Sci 70:993-999

33. Pekmezci D, Cakiroglu D (2009) Investigation of immunomodulatory effects of levamisole and vitamin E on Immunity and some blood parameters in newborn Jersey calves. Vet Res Commun 33:711-721 
34. Samanta AK, Dass RS, Rawat M, Mishra RC, Mehra UR (2006) Effect of dietary vitamin E supplementation on serum a-tocopherol and immune status of crossbred calves. Asian-Aust J Anim Sci 19:500-506

35. National Research Council (2001) Nutrient requirements of dairy cattle: Seventh revised edition, 2001//Nutrient requirements of dairy cattle. The National Academies Press; National Academies Press, Washington, DC

36. Gentry MK, Dalrymple JM (1980) Quantitative microtiter cytotoxicity assay for Shigella toxin. J Clin Microbiol 12:361-366

37. Muller D, Greune L, Heusipp G, Karch H, Fruth A, Tschape H, Schmidt MA (2007) Identification of unconventional intestinal pathogenic Escherichia coli isolates expressing intermediate virulence factor profiles by using a novel single-step multiplex PCR. Appl Environ Microbiol 73:3380-3390

38. Franck SM, Bosworth BT, Moon HW (1998) Multiplex PCR for enterotoxigenic, attaching and effacing, and Shiga toxin-producing Escherichia coli strains from calves. J Clin Microbiol 36:1795-1797

39. Paton AW, Paton JC (1998) Detection and characterization of Shiga toxigenic Escherichia coli by using multiplex PCR assays for stx1, stx2, eaeA, enterohemorrhagic E. coli hlyA, rfbO111, and rfb0157. J Clin Microbiol 36:598-602

40. Pirro F, Wieler LH, Failing K, Bauerfeind R, Baljer G (1995) Neutralizing antibodies against Shiga-like toxins from Escherichia coli in colostra and sera of cattle. Vet Microbiol 43:131-141

41. Koo HC, Park YH, Hamilton MJ, Barrington GM, Davies CJ, Kim JB, Dahl JL, Waters WR, Davis WC (2004) Analysis of the immune response to Mycobacterium avium subsp. paratuberculosis in experimentally infected calves. Infect Immun 72:6870-6883

42. Graham EM, Thom ML, Howard CJ, Boysen P, Storset AK, Sopp P, Hope JC (2009) Natural killer cell number and phenotype in bovine peripheral blood is influenced by age. Vet Immunol Immunopathol 132:101-108

43. Endsley JJ, Endsley MA, Estes DM (2006) Bovine natural killer cells acquire cytotoxic/effector activity following activation with IL-12/15 and reduce Mycobacterium bovis BCG in infected macrophages. J Leukoc Biol 79:71-79

44. Hope JC, Sopp P, Howard CJ (2002) NK-like CD8(+) cells in immunologically naive neonatal calves that respond to dendritic cells infected with Mycobacterium bovis BCG. J Leukoc Biol 71:184-194
45. Olsen I, Boysen P, Kulberg S, Hope JC, Jungersen G, Storset AK (2005) Bovine NK cells can produce gamma interferon in response to the secreted mycobacterial proteins ESAT-6 and MPP14 but not in response to MPB70. Infect Immun 73:5628-5635

46. Menge C, Dean-Nystrom EA (2008) Dexamethasone depletes gammadelta $T$ cells and alters the activation state and responsiveness of bovine peripheral blood lymphocyte subpopulations. J Dairy Sci 91:2284-2298

47. Johnson RP, Cray WC, Johnson ST (1996) Serum antibody responses of cattle following experimental infection with Escherichia coli O157:H7. Infect Immun 64:1879-1883

48. Corbishley A, Ahmad NI, Hughes K, Hutchings MR, McAteer SP, Connelley TK, Brown H, Gally DL, McNeilly TN (2014) Strain-dependent cellular immune responses in cattle following Escherichia coli O157:H7 colonization. Infect Immun 82:5117-5131

49. Chu A (2010) Immunomodulation by Shiga toxin 2. PhD Thesis, University of Saskatchewan http://hdl.handle.net/10388/etd-08252010-163545

50. Kieckens E, Rybarczyk J, Li RW, Vanrompay D, Cox E (2016) Potential immunosuppressive effects of Escherichia coli O157:H7 experimental infection on the bovine host. BMC Genomics 17:1049

51. Corbishley A, Connelley TK, Wolfson EB, Ballingall K, Beckett AE, Gally DL, McNeilly TN (2016) Identification of epitopes recognised by mucosal CD4(+) T-cell populations from cattle experimentally colonised with Escherichia coli O157:H7. Vet Res 47:90

52. Matthews L, Low JC, Gally DL, Pearce MC, Mellor DJ, Heesterbeek JAP, Chase-Topping M, Naylor SW, Shaw DJ, Reid SWJ, Gunn GJ, Woolhouse MEJ (2006) Heterogeneous shedding of Escherichia coli 0157 in cattle and its implications for control. Proc Natl Acad Sci U S A 103:547-552

53. Vande Walle K, Yekta MA, Verdonck F, de Zutter L, Cox E (2011) Rectal inoculation of sheep with $\mathrm{E}$. coli O157:H7 results in persistent infection in the absence of a protective immune response. Vet Microbiol 147:376-382

\section{Submit your next manuscript to BioMed Central and we will help you at every step:}

- We accept pre-submission inquiries

- Our selector tool helps you to find the most relevant journal

- We provide round the clock customer support

- Convenient online submission

- Thorough peer review

- Inclusion in PubMed and all major indexing services

- Maximum visibility for your research

Submit your manuscript at www.biomedcentral.com/submit
O Biomed Central 